\title{
WORKSHOP : Collective Architectures
}

\author{
YAZMÍN M. CRESPO CLAUDIO \& OMAYRA RIVERA CRESPO \\ Universidad del Turabo
}

A design-build workshop organized by Taller Creando Sin Encargos a collective founded by four female architecture professors; Yazmín M. Crespo, Andrea Bauzá, Irvis González y Omayra Rivera, at La Perla, a community outside the northern historic city-wall of Old San Juan, Puerto Rico. Together the professors share interests to revitalize deteriorated and abandon urban spaces with ephemeral interventions and participative workshops in an effort to redefine the conventional way of understanding the professional practice of architecture. The workshop invited students from the three architecture and design schools in Puerto Rico; Polytechnic University of Puerto Rico, University of Puerto Rico School of Architecture, Pontifical Catholic University of Puerto Rico and the School of Visual Arts in Old San Juan to work together with international architecture collectives Todo por la Praxis from Madrid, Spain; Arquitectura Expandida from Bogotá, Colombia; and FG Studio from New York City in three design-build projects together with the community.

The workshop included lectures by the three international architects' collectives, a design charrette, community presentations, final review, a round table and construction of the interventions from August 31 to September 7, 2013.

\section{THE COMMUNITY PARTICIPATION PRINCIPLES}

"... a process in which people have to think through what they want, consider some options, and work through what should happen." -David Wilcox
Participation means 'be part' of an activity or process and in the context of design and construction means that the inhabitant take part in decisions concerning the formal configuration, spatial segmentation and building materials that make up the project. Sometimes in designing conventional processes, architects studying types of buildings, construction techniques, formal solutions or functions and programs do not take into account the experience of the people in the environment. In participatory processes, however, both inhabitants and architects collaborate on an equal footing, in the design and construction of housing and public spaces so that there is not a mismatch between the spaces designed and living spaces. That is, people contribute their experience in the built environment and architects contribute their technical knowledge. This allows the inhabitants identify with the place, even before its construction, they feel that this belongs to them and identifies them. The participation of citizens in the construction and planning, dialogue and negotiation, allowing architects to create more spaces chords the practical and emotional needs of each person or group, to their collective and individual identity and, thus, contemporary modes of living.

Currently, the participation of citizens in the design and construction of their environment has assumed importance as it is progressively more difficult for architects and planners design spaces based on the particularities of each region because society is progressively diverse and globalized. The traditional identity of each place disintegrates before the coexistence of people of different cultures and to the flow of information that makes it possible to meet and characteristic features of different regions is integrated at any location without distinction. It is necessary, therefore, engage in dialogue with residents to understand their differences, needs, discover patterns that identify new communities and create new narratives, identities, which give way to emerging projects.

Presently, with the loss of traditions that characterize contemporary societies due to globalization, the search for identity through the built environment takes place mostly on an individual basis. In contemporary collective housing domestic spaces are customized but 


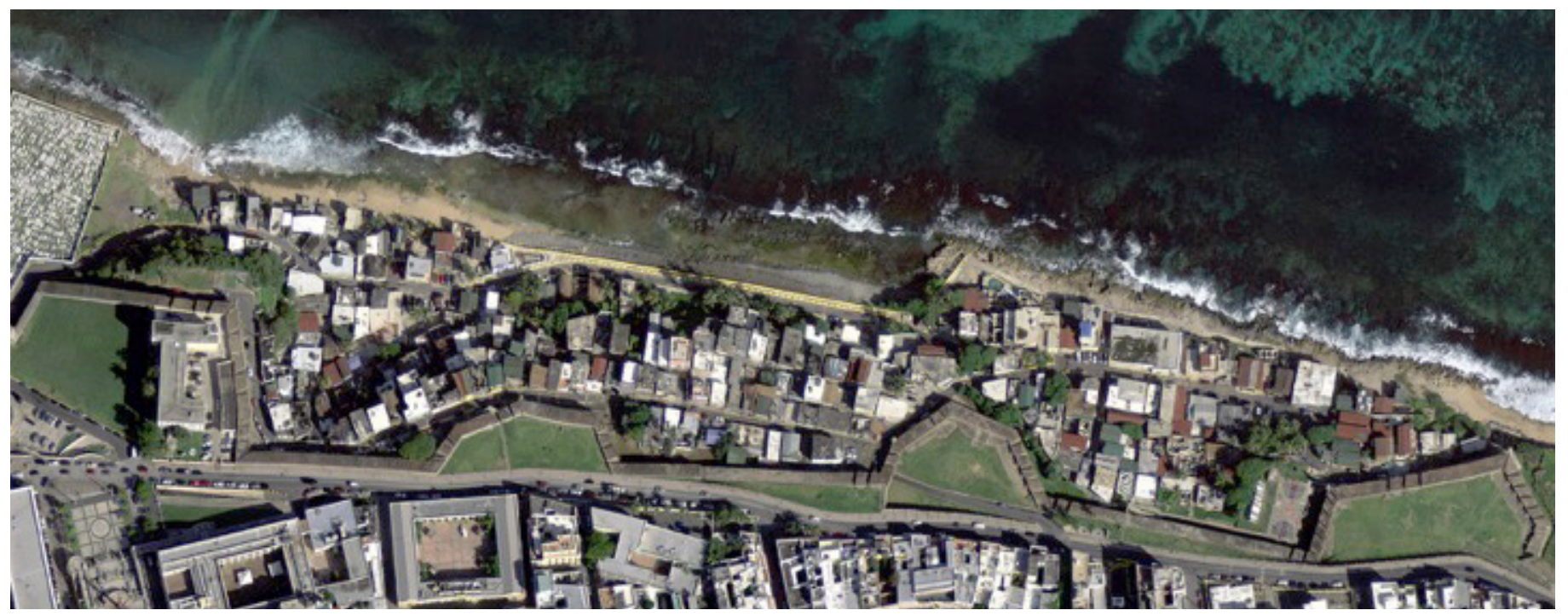

Figure 1: Aerial view of the community of La Perla

the exterior of buildings and the common spaces do not belong to anyone and are often permanent, that is, nothing distinguishes a community and therefore relates to all its inhabitants. For this reason the philosopher Marcus Steinberg states that "... a collective is a community whose members are linked by nothing else but the absence of an objective or absolute bond." The only link between the inhabitants of collective housing is the roof that covers them, like buildings, and the land they walk. Contemporary cities are composed, well, block and neutral public spaces that could be anywhere.

Under such conditions, in participatory processes it is intended that individuals collaborate in the design of distinctive communities from their characteristics and objectives, while keeping them define their particular identity. Among all they can imagine their future community and create the story that becomes a reality. As argued Hague "We interpret THUS planning for place identity as a process of developing a discourse, even writing a narrative. It is a selective way of imagining, acting and communicating about a place."

Both individual and collective identity should be considered in participatory processes as each inhabitant needs the built environment to become a reflection of their idiosyncrasies, the characteristics that distinguish it. By participating in the planning of the built environment citizens choose the features that define the place in which they live, that identifies them. Then, governed by their sense of belonging, to be part of a participatory process is also to be a member or part of a place.

This essay presents the WORKSHOP: Collective Architectures, a participatory process in the community of La Perla in Old San Juan, Puerto Rico. A project organized by the collective Taller Creando Sin Encargos. The project involved the occupants, mostly children to work both in the design and construction of the interventions in forsaken spaces of the community.

\section{WORKSHOP: COLLECTIVE ARCHITECTURES - INTERNATIONAL MEETING IN PUERTO RICO}

The current crisis has not only provided a gap in the traditional practices of the architect, this has forced us to rethink the profession from its practical perspective to its immediate potential of achieving positive change in the city. From a social place that negotiates the expansion of optimism on participation, cooperation in exceptional situations; collectives of architects work to escape the traditional design practice and encourage transformations in the city. The challenge is to create architecture that generates social and cultural circumstances were balanced situations are drawn, and where we are all protagonists of the city.

\section{THE BRIEF}

The WORKSHOP: Collective Architectures does not include flamboyant nor star-architects but emphasizes that the masterplan is an anachronism of our society. Thus, is not architecture of mega-structures that occupy a prominent territory within a city or community, but specific, local and possibly transient proposals. During the workshop students, professors, and the collectives utilize and explore the mechanisms for recovering the position of the designer - more advocate - in the public sphere. It is about knowing and understanding that we need to be accomplices of new urban practices, self-organized work and site-specific projects.

The collectives (designers, students, volunteers) work in the public sphere as scanners from where sequences of implied networks and relationships are constructed. They overview, preview, focus and then scan the place. In the scanning operation public spaces are put in dialogue through the subject; the community of La Perla. The network questions the nature of architectural practice involving around forty students, three international designers [Todo por la Praxis, Arquitectura Expandida, and FG Studio] in the process of participation and self-managing empty spaces in urban contexts. In this process there is no space for star architects or architecture. The significance of the projects is not the end result, but the process itself. 
The place of intervention, La Perla, established since the late ninth century outside the walls of Old San Juan, extends about 600 meters from the Castillo de San Cristobal to Santa María Magdalena Cemetery (Figure 1). The community has a history of ups and downs and a lot of the buildings are abandoned and wounded by caresses of the climate and the Atlantic Ocean. In the 2000 census the population was 338 people, 98 of these 29 homes are vacant. The community has overcome obstacles through time promoting the participation of its residents through activities and cultural events. These residents have been fighting for their landscape scented of salt and shortcuts painted of nostalgia and dressed of the passage of time.

The spaces for the interventions were chosen by the children of La Perla through a scavenger hunt of photographs/images. The image is used as the best resource that helps describe memories, actions and dreams. According to sociologist Douglas Harper "The idea of breaking the frame is that photographs may lead an individual to a new view of their social existence." In this case, photography as a game helped the children to see their community spaces from another point of view and to rethink about them. Children were chosen for this exercise because in the neighborhood are those who most use the common spaces in creative ways. Each child had a disposable camera and a series of questions as: which is your favorite space? where do you play? where do you want to play but you can't? where do you go to observe the sea? take a photograph of a space representative of your community? Subsequently, an exhibition was made with the photographs and three spaces of interventions were selected (Figure 2).
As noted in the introduction of the exhibit Design with the other 90\% "This emphasis on "designing with" expands the traditional definition of design to include the creative activity of marginalized population who are harnessing their energy and skill in ambitious and communal ways to build a better world for themselves and the city the live in." explains Cara McCarty.

Students from the different universities who participated in the workshop were divided into groups and asked to develop design proposals for each of the spaces selected by the community, all in less than a week. One of the requirements was to used recycled materials and collaborate with the community in the narrative of design. The collective Taller Creando Sin Encargos, local volunteers and the international architects reviewed all the proposals and selected the best suited for each place of intervention accordingly to the community needs (Figure 3).

Although the projects were temporary insertions, they acted as urban prostheses in deteriorated spaces of social encounters within the community. The "urban disobediences" organized through collectives, volunteers and students constructed new "situations" to be added in unfinished urban cartographies. They were fragmented scenes of a community seen in frames, where each intervention became an event that formed part of an experimental urbanism, one that traces notes about urban practices. The intervention Vista Mar, a children's clubhouse in an abandoned structure, was renewed and turned into a playground together with the children from the sector; nickname los gallitos (Figure 4). The steps, contiguous the community
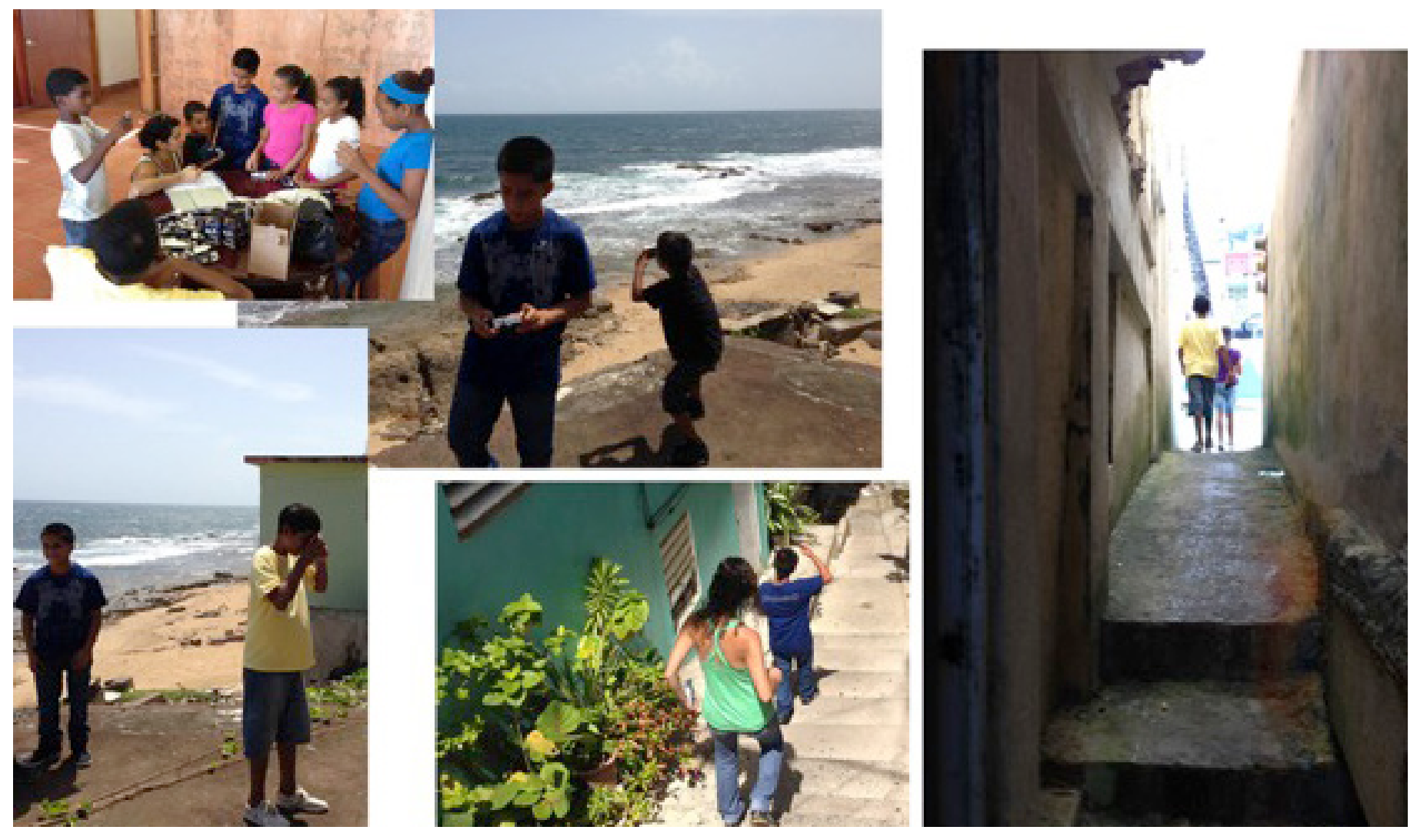

Figure 2: Scavenger Hunt of photographs with children of La Perla 

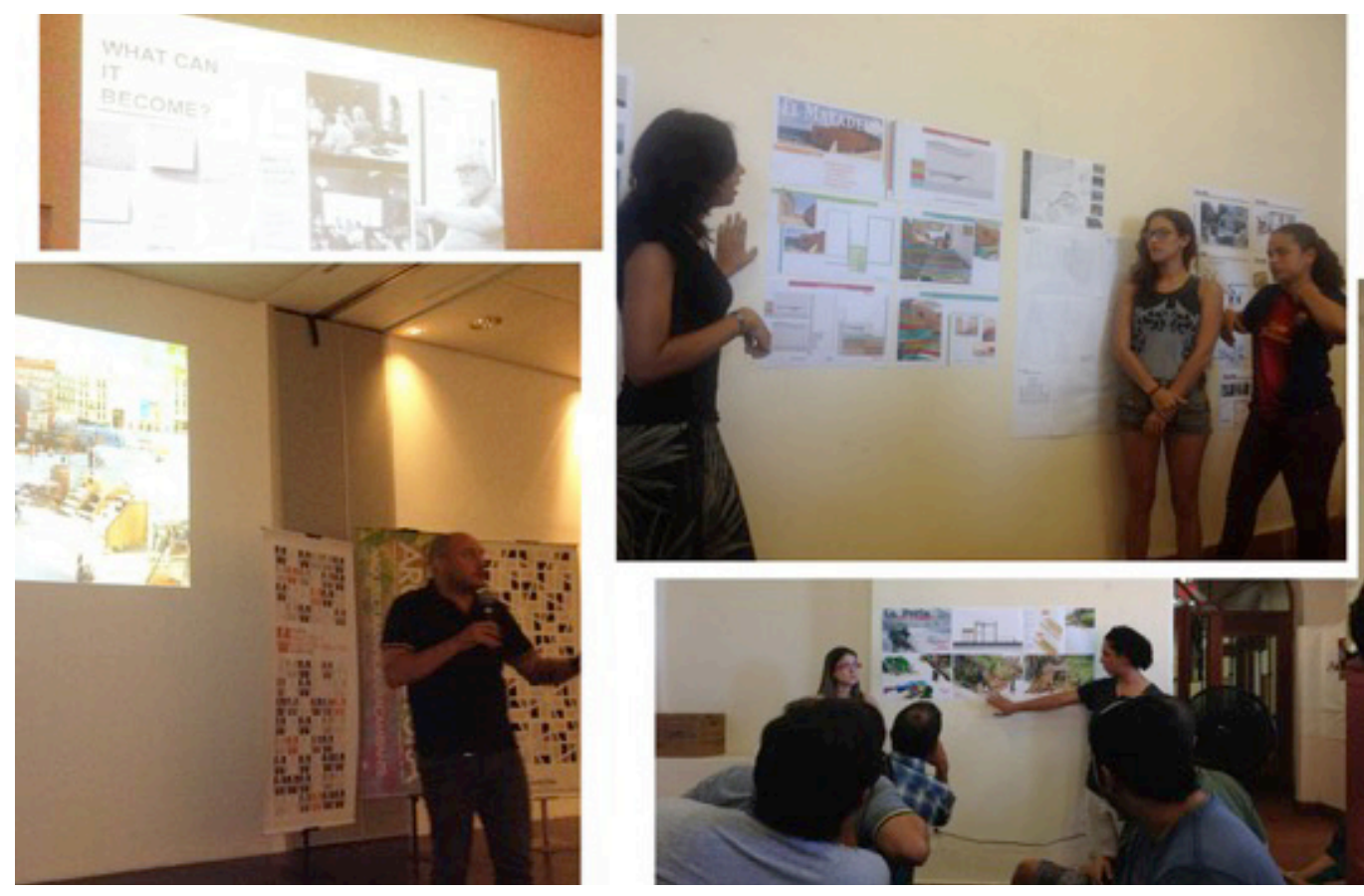

Figure 3: Reviews and Presentations

center, were rehabilitated as colorful stands to see the spectacle of the sea. Lastly, Luigi's Stair in the sector of waipao, is an intervention that the students built on the beach. They completed a deteriorated stair to recuperate the access to the water (Figure 5). The project that included the help of local surfers still holds its presence at the beach. The stair-sitting bench has become a meeting space and the threshold for locals to become one with the waves.

\section{THE OBJECTIVES}

The main objective of the workshop was to offer students the opportunity to participate in a collaborative design-build project with students from other universities. In an effort to recognize the community as more than a self-constructed informal settlement, the workshop pondered on the idea of understanding it as a composite organism. This helped students to comprehend architecture's social responsibility to urban space and its users. For all to dialogue about an architecture that represents the need of the people and reflects on forgotten and deteriorates spaces and possibly recycled materials. From a more critical perspective, to observe design-build projects as an essential part of architectural education. Furthermore, the Workshop intended for students to explore tactical and flexible construction solutions in small-scale interventions that are immediate and low-cost. The interventions dialogued about the necessity of places for social encounter and the importance of participation and communication.

\section{THE FINDINGS}

Behind the architectural object are: processes, images, texts, drawings and maps. Architecture challenges conventions, it explores the form, builds atmospheres and sometimes it is an act of cultural resistance. We learned that the design and build exercises are an opportunity to actively participate in research and creative work. The workshop provided students the opportunity to collaborate with international emerging practices. They could participate in the project before, during and after construction. Finally, they could understand that design is a collaborative effort and a manifestation of culture.

Looking back at the participatory design the response to our first call for students to participate was moving and strong. We received over forty students and volunteers to design and build together with the community an effusing and exemplary process. It addressed the social role of architecture. It evidences that architecture initiates social change by observing and understanding community needs.

The team of architects behind the Workshop proposed methodologies that grasp valuable opportunities for design-build projects that result from a space of collaboration between architects and communities. The findings discussed at the round table, the last activity after the construction helped reflect on the importance of the persons that will occupy the interventions. More importantly, the narrative is one of discovered and recommended conditions that privilege the community over the plan.

\section{ENDNOTES}

1. Steinberg, Marcus. "What is Collective?", New forms of collective housing in Europe. Basel: Birkhäuser Verlag AG, 2009, p.46

2. Hague, Cliff. Place identity, participation and planning. New York: Routledge, 2005, p.10

3. Harper, Douglas. Talking about pictures: a case of photo elicitation. Visual Studies, vol. 7, num. 1, 2002, p.21

4. McCarty, C. Design with the other $90 \%$ Cities. New York: Cooper-Hewitt, National Design Museum, 2011, p.8 


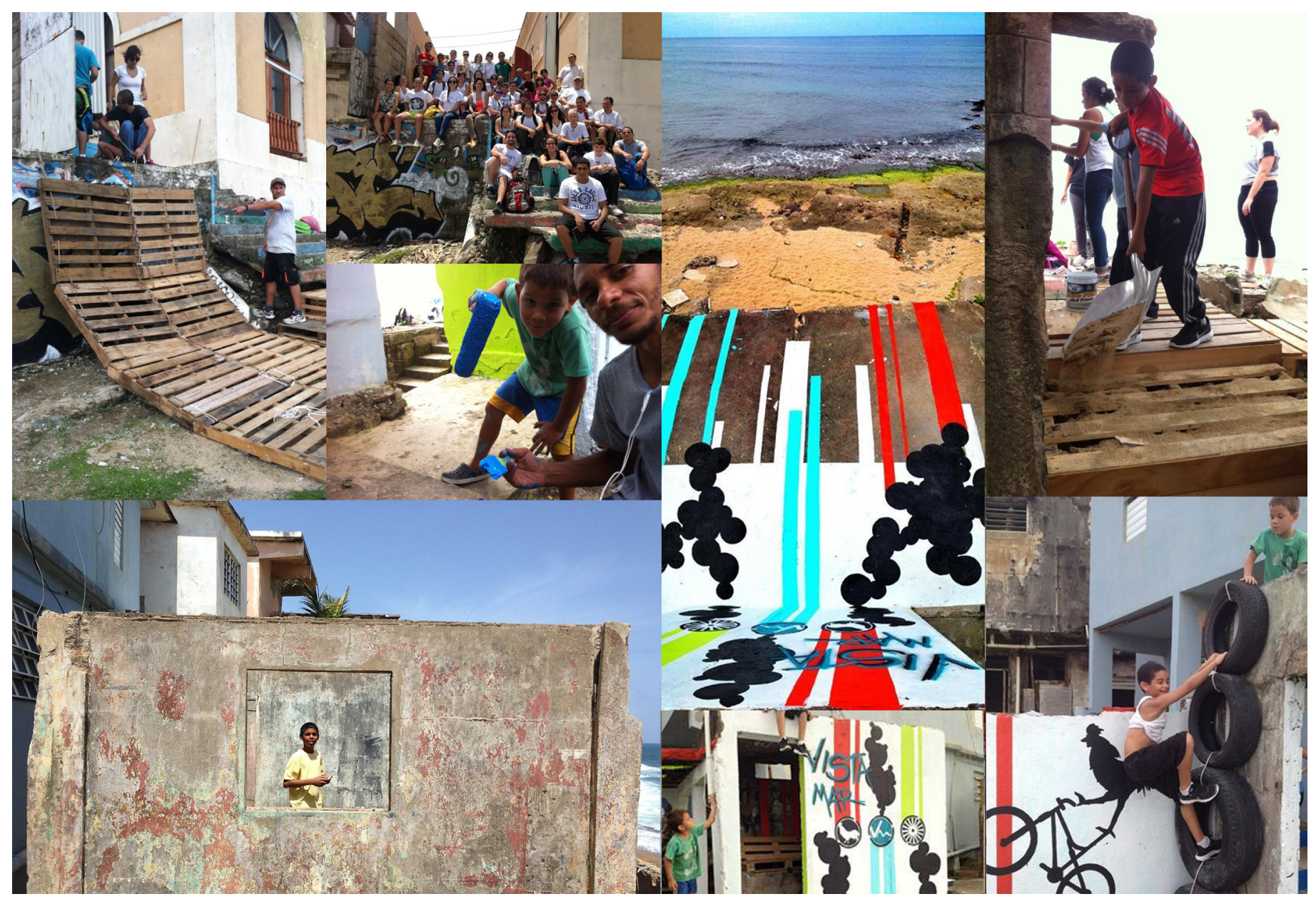

Figure 4: Vista Mar's Clubhouse.
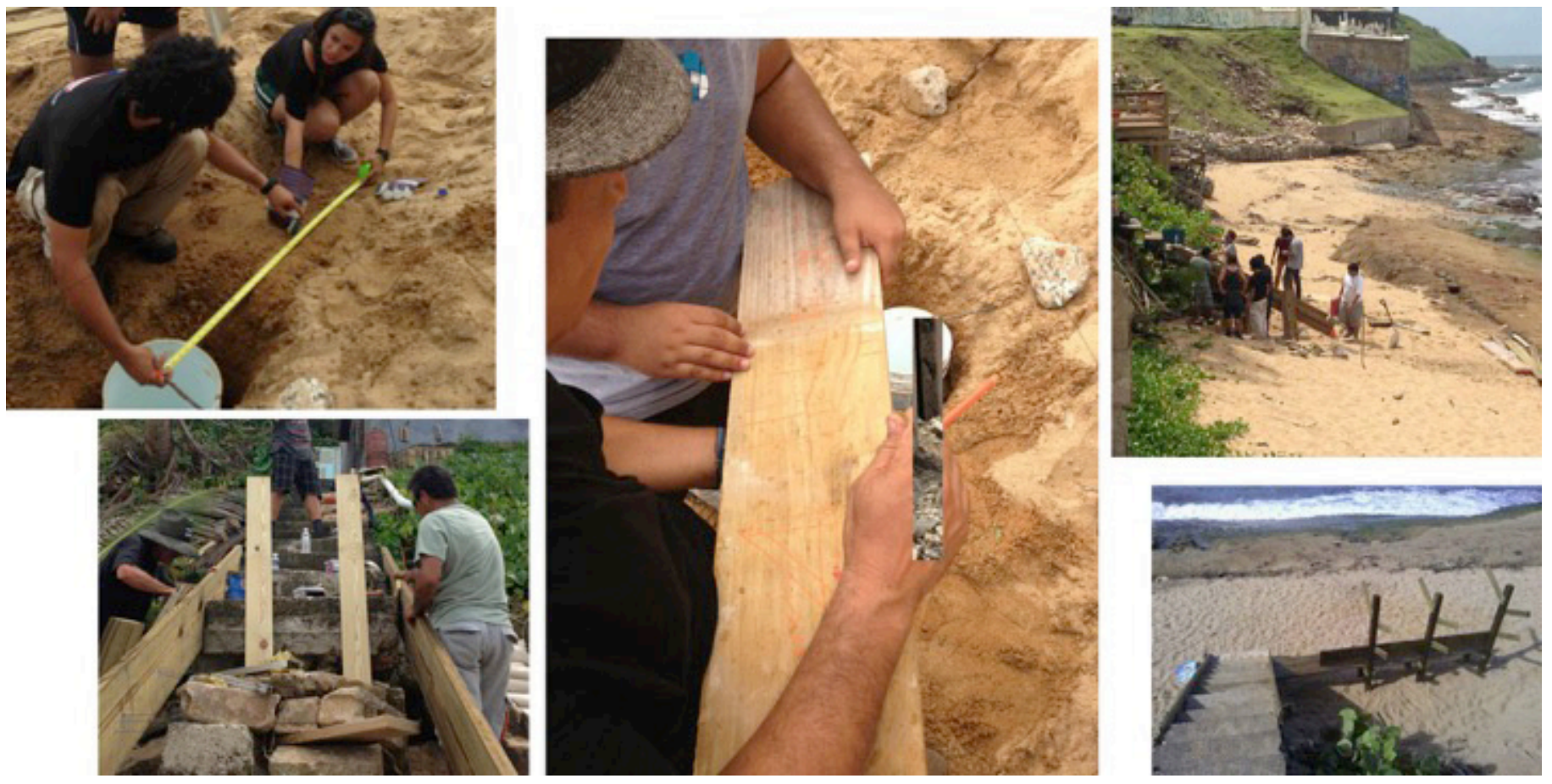

Figure 5: Luigi's Stair 